\title{
Unihemispheric sleep and asymmetrical sleep: behavioral, neurophysiological, and functional perspectives
}

\section{Gian Gastone Mascetti \\ Department of General Psychology, University of Padova, Padova, Italy}

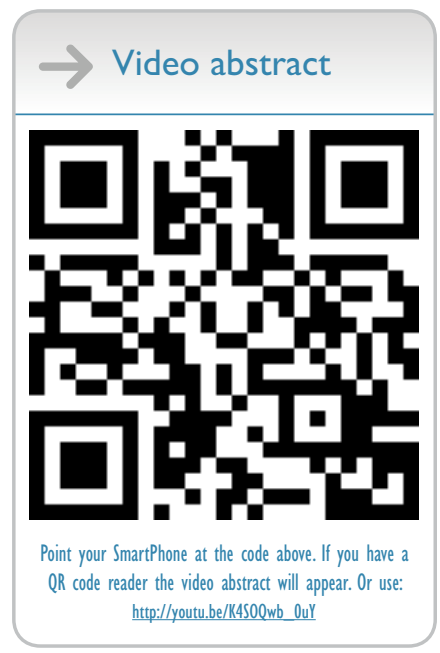

Correspondence: Gian Gastone Mascetti Department of General Psychology, University of Padova,Via Venezia 8, 35 I 3 I Padova, Italy

Tel +3949827 6669

Fax +39498276600

Email giangastone.mascetti@unipd.it
This article was published in the following Dove Press journal:

Nature and Science of Sleep

12 July 2016

Number of times this article has been viewed

\begin{abstract}
Sleep is a behavior characterized by a typical body posture, both eyes' closure, raised sensory threshold, distinctive electrographic signs, and a marked decrease of motor activity. In addition, sleep is a periodically necessary behavior and therefore, in the majority of animals, it involves the whole brain and body. However, certain marine mammals and species of birds show a different sleep behavior, in which one cerebral hemisphere sleeps while the other is awake. In dolphins, eared seals, and manatees, unihemispheric sleep allows them to have the benefits of sleep, breathing, thermoregulation, and vigilance. In birds, antipredation vigilance is the main function of unihemispheric sleep, but in domestic chicks, it is also associated with brain lateralization or dominance in the control of behavior. Compared to bihemispheric sleep, unihemispheric sleep would mean a reduction of the time spent sleeping and of the associated recovery processes. However, the behavior and health of aquatic mammals and birds does not seem at all impaired by the reduction of sleep. The neural mechanisms of unihemispheric sleep are unknown, but assuming that the neural structures involved in sleep in cetaceans, seals, and birds are similar to those of terrestrial mammals, it is suggested that they involve the interaction of structures of the hypothalamus, basal forebrain, and brain stem. The neural mechanisms promoting wakefulness dominate one side of the brain, while those promoting sleep predominates the other side. For cetaceans, unihemispheric sleep is the only way to sleep, while in seals and birds, unihemispheric sleep events are intermingled with bihemispheric and rapid eye movement sleep events. Electroencephalogram hemispheric asymmetries are also reported during bihemispheric sleep, at awakening, and at sleep onset, as well as being associated with a usedependent process (local sleep).
\end{abstract}

Keywords: sleep, asymmetry, unihemispheric, dolphins, seals, birds

\section{Introduction}

Sleep was earlier defined as a periodically necessary behavior, with a rhythm relatively independent from the environment and with an almost complete interruption of sensory and motor functions. ${ }^{1}$ However, it is now known that motor signals reach motoneurons, although their output is reduced during non-rapid eye movement (NREM) sleep and actively inhibited during REM sleep. Sensory messages impinge the thalamus and the cortex, but the increase in sensory thresholds makes the subject progressively unresponsive to external stimuli as sleep deepens. Sleep is characterized by a reduction of motor activity (except REM as well as facial and digital twitches), the search for a sensorily isolated and protected place, and the assumption of characteristic body postures.

Sleep can be studied by observing and recording the body signs of sleep behavior, but to detect its physiological and psychological organization, it is indispensable to 
record electrographic signs: electroencephalogram (EEG), movements of eyes (electrooculogram [EOG]), muscle tone (electromyogram [EMG]), electrocardiogram (ECG), breathing frequency, and body temperature. These parameters allow distinguishing wakefulness from sleep, NREM from REM sleep, and the transitions from wakefulness to sleep and sleep to awakening.

In mammals, the EEG wave pattern changes as follows: during wakefulness, it consists of low-amplitude highfrequency waves (beta rhythm, desynchronized EEG); at onset of NREM sleep, a theta rhythm predominates (stage 1); thereafter, the EEG becomes progressively more synchronized at subsequent stages, and at stage 4, it is dominated by high-voltage and low-frequency waves (delta waves, slow-wave sleep [SWS], synchronized EEG); concurrently, the muscle tone progressively declines. In the course of NREM, the EEG pattern changes to low voltage and fast waves (desynchronized EEG), but sleep behavior persists, the muscle tone is actively inhibited, and bursts of saccadic eye movements (REM) are recorded in the EOG. In humans, each cycle of an NREM and REM episode lasts 90-100 minutes. During NREM, blood pressure, heart and respiration rates, and body temperature decrease. During REM sleep, blood pressure, heart rate, and respiration rate increase and become irregular, and there is a general activation of brain and autonomic system, accompanied by male penile erection and female clitoral engorgement. Thermoregulation is mainly abolished during REM sleep; therefore, thermoregulatory mechanisms cannot be brought into function. Sleep is not associated with a reduction of brain activity; by contrast, neurons remain fully active during sleep although they show a different discharge pattern. Overall, the role of sleep on the brain and body functions is connected to the patterns of EEG waves, dreaming, the change of discharge pattern of neurons, the synthesis and degree of release of brain chemical substances, synaptic homeostasis, and others.

A function attributed to sleep is the restoration of brain energy metabolism, consisting in the replenishment of brain glycogen stores. ${ }^{2}$ The stores of glycogen in astrocytes are progressively depleted during waking, associated with a progressive propensity to sleep. During NREM sleep, the glycogen stores are progressively replenished and brain energy metabolism is restored; the process is less efficient during REM sleep. The depletion of glycogen during waking causes the accumulation of adenosine, which has been proposed as a putative somnogen able to trigger sleep onset and EEG synchronization. ${ }^{1,3,5}$
A pulsatile release of some hormones during sleep may be associated with body restoration and homeostasis..$^{3-6}$ Cortisol level reaches a nadir during nocturnal sleep but slowly increases during the second half of the sleep period, and its acme is reached just before and at onset of awakening. The growth hormone peaks during the first half of the sleep period. Prolactin secretion peaks at the middle of the sleep period and decreases when awakenings occur during sleep. Pituitary thyroid-stimulating hormone secretion increases during nocturnal sleep, while the secretion of triiodothyronine and thyroxine decreases. It has been indicated that hypothalamic growth hormone-releasing hormone (GHRH) promotes sleep, while corticotropin-releasing hormone favors awakening and wakefulness. Finally, sleep deprivation causes a decrease in body sensitivity to insulin, a decrease of leptin (inhibits hunger), and an increase of gherlin (stimulates hunger).

Sleep keeps up the efficiency of the immune system, thus favoring health and the probability of survival. ${ }^{7-10} \mathrm{An}$ infectious illness is accompanied by an intense somnolence or sleepiness probably because compelling to rest and more sleep favor the processes of healing. Insufficient or inadequate sleep increases the susceptibility to viral infections (cold, flu) or the ability to be affected by infection spread. The cytokines interleukin (IL)-1 and IL-6, as well as the trophic factor tumor necrosis factor-1, act on the hypothalamic thermostat, triggering fever and NREM-SWS.

Sleep and thermoregulation are closely linked. ${ }^{11-15}$ Animals select an appropriate environment for sleeping that facilitates minimal thermal loss and maximal thermal conservation. The preoptic area of anterior hypothalamus (POAH) shares the mechanisms of sleep regulation and thermoregulation. Mild heating of POAH reduces sleep latency and promotes NREM sleep and SWS, while its cooling causes opposite effects. During NREM sleep, there is a decrease of body and brain temperatures, caused by a reduction of metabolic rate, an increase of heat loss, and a decrease of heat production all aimed at energy conservation.

Memory encoding and consolidation are functions attributed to sleep. ${ }^{16-19}$ Overall, memory consolidation is impaired in sleep-deprived subjects compared with nondeprived ones. However, for declarative memory consolidation, data are controversial because impairment or nonimpairment would depend on specific aspects of the memory task, such as the presence of emotional or neutral components. Motor learning performance and visual perceptual learning are significantly improved after sleep, but they are not after both an equivalent wake period or after sleep deprivation. Overall, SWS and REM sleep before training are indispensable for initial 
memory encoding, while posttraining SWS and REM sleep are crucial for memory consolidation and the associated neural plasticity.

Synaptic potentiation and strengthening is the neural correlate between sleep and memory consolidation. It has been suggested that the brain would become oversaturated in a short period of time if all the waking-activated synapses are reinforced by subsequent sleep, thereby causing a reduction of the capacity to acquire learning and memories. Furthermore, not all neural traces left by the waking experience should be relevant and have to be consolidated during sleep. It has been suggested ${ }^{20,21}$ that the synapses involved in new significant memories are selectively strengthened during sleep, while synapses activated by nonsignificant experiences are selectively weakened. Selective synaptic weakening restores brain circuitry to a certain baseline functional level, fully predisposing the brain toward new learning and experiences during subsequent wakefulness.

\section{Unihemispheric sleep}

Electrographic patterns, behaviors, neural mechanisms, and functions have been described taking into account the idea that sleep involves the whole brain and the body at the same time. Hemispheric asymmetries of EEG wave patterns have been found during bihemispheric sleep (BS), as well as a higher amount of sleep in specific cortical areas associated with specific sensory or motor experiences during wakefulness (local sleep). Closure of both the eyes, symmetric body muscular hypotonia or atonia, and REMs are associated with BS. Some animals show a different sleep behavior because sleep is induced in only one hemisphere, while the other hemisphere remains awake or it is awakened, termed as unihemispheric sleep. In some aquatic mammals, sleep and wakefulness periods alternate between the hemispheres, and it is the only way of sleeping. In other animals (seals and birds), unihemispheric sleep is a transitory sleep event intermingled with BS. Unihemispheric sleep is currently associated with asymmetric eye closure/opening and particular body sleep postures. Electrographically, unihemispheric sleep consists of an EEG composed of waves of low frequency and high amplitude (slow waves, synchronized EEG) recorded in one hemisphere (sleeping) and an EEG composed of a mixture of high- and low-amplitude waves (intermediate state) or of high-frequency and low-amplitude waves (desynchronized EEG) in the other hemisphere (awake). ${ }^{22,23}$ Unihemispheric sleep in cetaceans and pinnipeds is named as unihemispheric slow-wave sleep or USWS, while unihemispheric sleep in birds is named as unihemispheric-monocular sleep (Un-Mo sleep). SWS in both hemispheres is named bihemispheric SWS (BSWS).

\section{Unihemispheric sleep in cetaceans}

Sleep behavior was studied in some cetaceans, including bottlenose dolphins, common porpoise, the Amazonian dolphin, pilot whale, and beluga whale. In the pilot whale ${ }^{24,25}$ (a type of cetacean), was recorded an asymmetrical EEG pattern composed of high-amplitude, slow-frequency waves in one hemisphere and simultaneous slow-amplitude highfrequency waves in the other hemisphere, defined as an EEG pattern of "quiet wakefulness" (Figure 1). Dolphins spent almost two thirds of day time in wakefulness showing a typical bilateral wake desynchronized EEG pattern and an USWS pattern in the remaining daily third. Several studies have confirmed and studied the USWS in cetaceans. ${ }^{22,26-31}$ USWS alternated between the hemispheres; in one single session, USWS occurred more in one hemisphere, while in another session, it was more frequent in the other one, but in the long run, both hemispheres benefited from an equal amount of sleep. ${ }^{22,32}$ BSWS (delta range) was never observed in dolphins, porpoises, and whales for more than a few seconds. ${ }^{33}$ The use of a telemetry method facilitated the understanding that for one brief period of time (duration not reported by Ridgway ${ }^{29}$ ), sleep-like EEG activity appeared in both hemispheres in bottlenose dolphins. ${ }^{29}$

In cetaceans, the correlation between eye closure/opening and USWS has been an undefined issue perhaps because these are not always correlated and/or due to the difficulty of detecting eye state during USWS while the animal swims or rests in a particular body position. It has been reported that dolphins sleep with one eye closed and one eye open in order to monitor the environment. ${ }^{34,35}$ An asymmetry state during USWS in bottlenose and Amazon dolphins was confirmed, ${ }^{28,36}$ but it was pointed out that one eye could be either open or closed when the contralateral hemisphere was in SWS. A subsequent study revealed that the eye contralateral to the hemisphere showing SWS is usually closed in dolphins. ${ }^{37}$ Subsequently, in beluga and bottlenose dolphins, a closer association between USWS and eye state asymmetry has been confirmed $^{38}$ : the eye contralateral to the sleeping hemisphere was mostly closed or in an intermediate state, while the eye contralateral to the waking hemisphere was almost always open or in an intermediate state. However, the stimulation of the open eye during an episode of USWS awakened the animal when the contralateral hemisphere was either awake or asleep, indicating that the hemisphere/open eye is in control of behavior. ${ }^{36,39}$ Bilateral eye opening indicated waking, while 


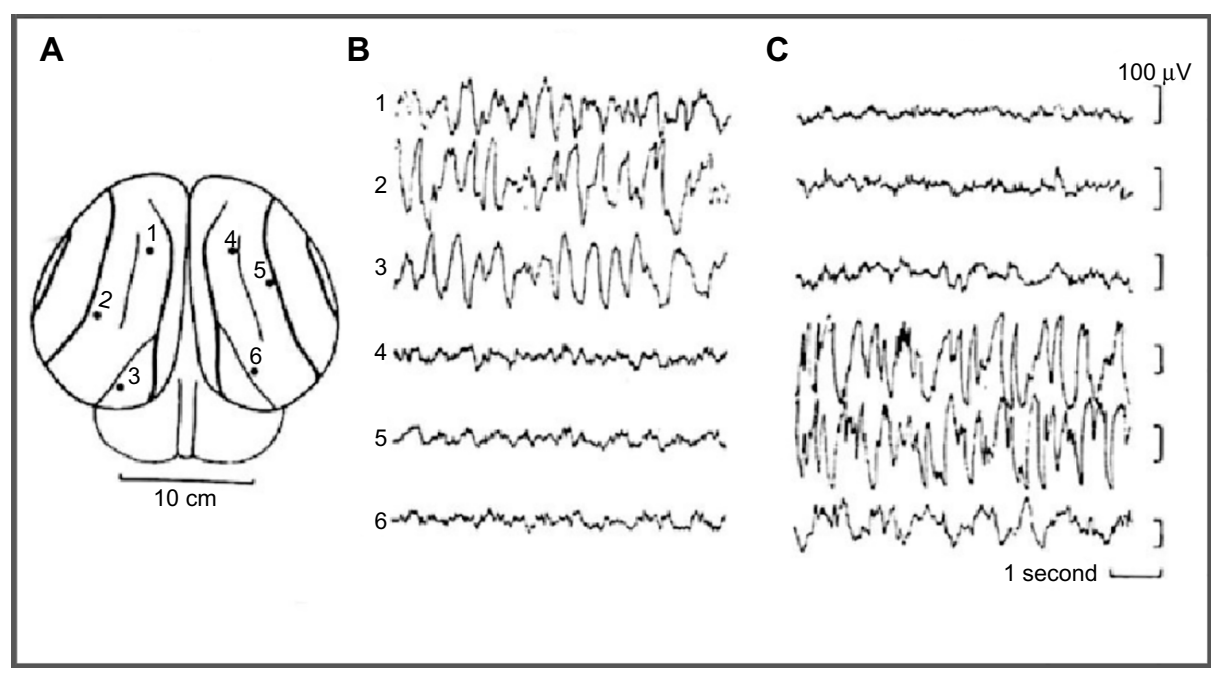

Figure I EEG recorded from occipital-parietal derivations.

Notes: (A) EEG in a bottlenose dolphin during USWS. (B) EEG of left hemisphere. (C) EEG of right hemisphere. Reprinted from Brain Research, Vol I34, Mukhametov LM, Supin AY, Polyakova IG. Interhemispheric asymmetry of the electroencephalographic sleep pattern in dolphins, Pages no 58I-584, Copyright (C) (I977) with permission from Elsevier.

Abbreviations: EEG, electroencephalogram; USWS, unihemispheric slow-wave sleep.

bilateral eye closure was rare $(<2 \%$ of observation time). White whale also showed USWS not strictly associated with eye state asymmetry. ${ }^{40}$ Thus, cetaceans' eye state does not accurately reflect the sleep state because there are occasions ( $<1$ minute) when they could be independent. ${ }^{40}$

In cetaceans showing USWS, no EEG signs of REM sleep have been reported. . $2,27,28,33,159$ However, behavioral signs such as penile erection, eyelid movements, and muscle twitching, which are currently observed during terrestrial mammalian REM sleep, have been occasionally observed in cetaceans..$^{27,33,39,41-43}$ On the one hand, these behavioral features are not considered sufficient indicators of REM sleep in terrestrial mammals, and on the other hand, they also occur during wakefulness in cetaceans ${ }^{33}$ Existing data do not support the presence or absence of REM sleep in dolphins, but some author ${ }^{33}$ suggest that it could be present either in a modified form and/or as a short-lasting event that is therefore difficult to be detected. Subcortical structures and probably the whole half of the brain are involved in USWS because thalamic nuclei display a low-frequency electrical activity correlated with the ipsilateral sleeping cortex. ${ }^{44}$

Bottlenose, Amazonian, and Pacific white-sided dolphins slowly swim or hover on the water surface when they are in USWS, ${ }^{26,32}$ while during constant swimming, they reach the surface and breathe but maintain the USWS condition. Porpoises do not hover but swim continuously and emerge to breathe. In addition, bottlenose dolphins have also been observed to resting and sleep at the bottom of the pool or tank with one or both eyes open, interrupted by surfacing to breathe. Cetaceans need to surface regularly for breathing ${ }^{52}$; therefore, the movements and reflexes needed for such behavior are incompatible with BSWS and REM sleep, which show reduced or abolished muscular activity. Therefore, sleep is triggered in one hemisphere, leaving the other awake and in control of motor behavior. ${ }^{28,33}$ When they swam in groups, it was observed that the open eye was directed toward the center of the group while the closed eye faced away. ${ }^{45,46}$ Therefore, they maintained visual contact with the group. In fact, when the dolphins changed position within the group, the open/ closed eye pattern was inverted. ${ }^{45,46}$

\section{Unihemispheric sleep in seals (Pinnipedia)}

Seals sleep in water and on land. EEG and sleep behavior have been studied in Otariidae (eared seals), in Phocidae (true seals), and in Sirenia (manatee). Eared seals (northern fur seals) show BSWS, bihemispheric REM sleep, as well as typical USWS in water and on land (Figure 2)..$^{26,33,47,48}$ The degree of EEG asymmetry was not equal across the dorsal cerebral cortex, but it was the greatest in the occipital-lateral and parietal derivations and the smallest in the frontal-medial ones. ${ }^{50}$

On land, BSWS predominates over USWS, but in water, the amount of USWS increases: USWS percentage on land is $41.6 \%$, while in water, it is $66 \%{ }^{49}$ Seals revert to more USWS when water conditions render BSWS less convenient or feasible because of the need to breathe while sleeping. For the same reason, the amount of REM sleep in water is lower than that on land. ${ }^{51}$ 
A

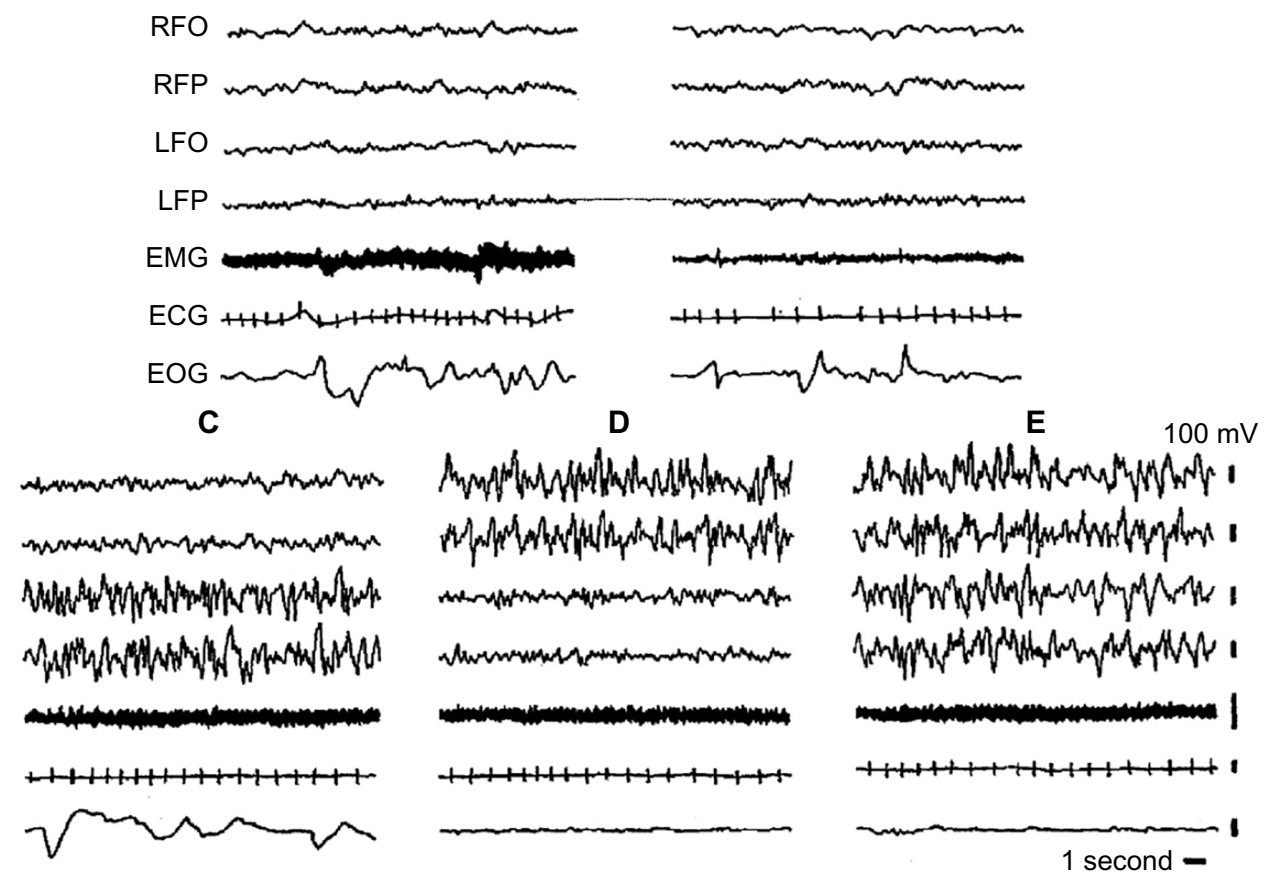

B

Figure 2 Electrographic recordings of the Cape fur seal.

Notes: (A) Wakefulness; (B) REM sleep; (C) left USWS; (D) right USWS; (E) BSWS. Reprinted with permission from Neuroscience Letters, Vol I43, Lyamin OI, Chetyrbok IS, Unilateral EEG activation during sleep in the Cape fur seal, Arctocephalus pusillus. Pages 263-266, Copyright @ (1992) with permission from Elsevier.

Abbreviations: BSWS, bihemispheric slow-wave sleep; ECG, electrocardiogram; EEG, electroencephalogram; EMG, electromyogram; EOG, electrooculogram; LFO, EEG from left fronto-occipital cortex; LFP, left frontoparietal cortex; REM, rapid eye movement; RFO, right fronto-occipital cortex; RFP, EEG from right frontoparietal cortex; USWS, unihemispheric slow-wave sleep.

In water, fur seals adopt a particular body posture during USWS, which allows them to sleep and breathe: they lie on one side keeping one of the front flippers in water paddling continuously, while the other three flippers are kept in air, probably for lowering heat $\operatorname{loss}^{52,53}$; the nostrils are kept out of water for breathing (Figure 3). The hemisphere contralateral to the moving flipper tends to be awake (desynchronized EEG), thereby allowing the motor commands for paddling, while the other hemisphere is less desynchronized or in SWS. As soon as the seal falls into REM sleep, the flipper movement ceases and the seal's head sinks. ${ }^{51}$ USWS is accompanied by unilateral eye closure.

USWS has been also recorded in Cape fur seals while they were on land, thereby not linked to the need for breathing. The hemisphere contralateral to the open eye was more awake (EEG desynchronized) than the other hemisphere connected to the closed eye. ${ }^{47}$ EEG in these seals was not recorded during USWS in water. During an episode of USWS on land, these eared seals adopt the same body posture as they do when they have USWS in water, thereby not linking it to breathing. ${ }^{47}$ In a species of sea lions, the Stellar, USWS was also associated with reaching the surface during sleep for breathing, but, similar to dolphins, USWS has been recorded while they were swimming. ${ }^{54}$ Sleep has been also studied in three other species of true seals. ${ }^{28,54-58}$ In these seals, EEG recordings revealed that they had only BSWS and REM sleep and that USWS was totally absent both in water and on land. In water, they adopt two sleep positions: 1) float at the surface and raise the head for breathing without arousing; 2) in deep water, hold the breath while sleeping bihemispherically and periodically surfacing for breathing. On land, they sleep and breathe. In different families of seals, different solutions have been worked out for the same need to breathe and sleep while they are in water. Manatees (species of the order Sirenia) display exclusive aquatic swimming in shallow waters. USWS has not been recorded in Caribbean manatees although the presence of USWS cannot be excluded. Amazonian manatees showed USWS, BSWS, and REM sleep and they remained motionless at the bottom of the water during all stages of sleep. ${ }^{59}$ Walrus sleeps both in water and on land. ${ }^{158}$ On land, walrus showed BSWS (both eyes closed), paradoxical sleep, and brief episodes of interhemispheric EEG asymmetry or USWS. The eye contralateral to the hemisphere showing SWS was closed, while the eye contralateral to the hemisphere with low-voltage waves was open. In water, sleep occurred mainly while the walrus was 


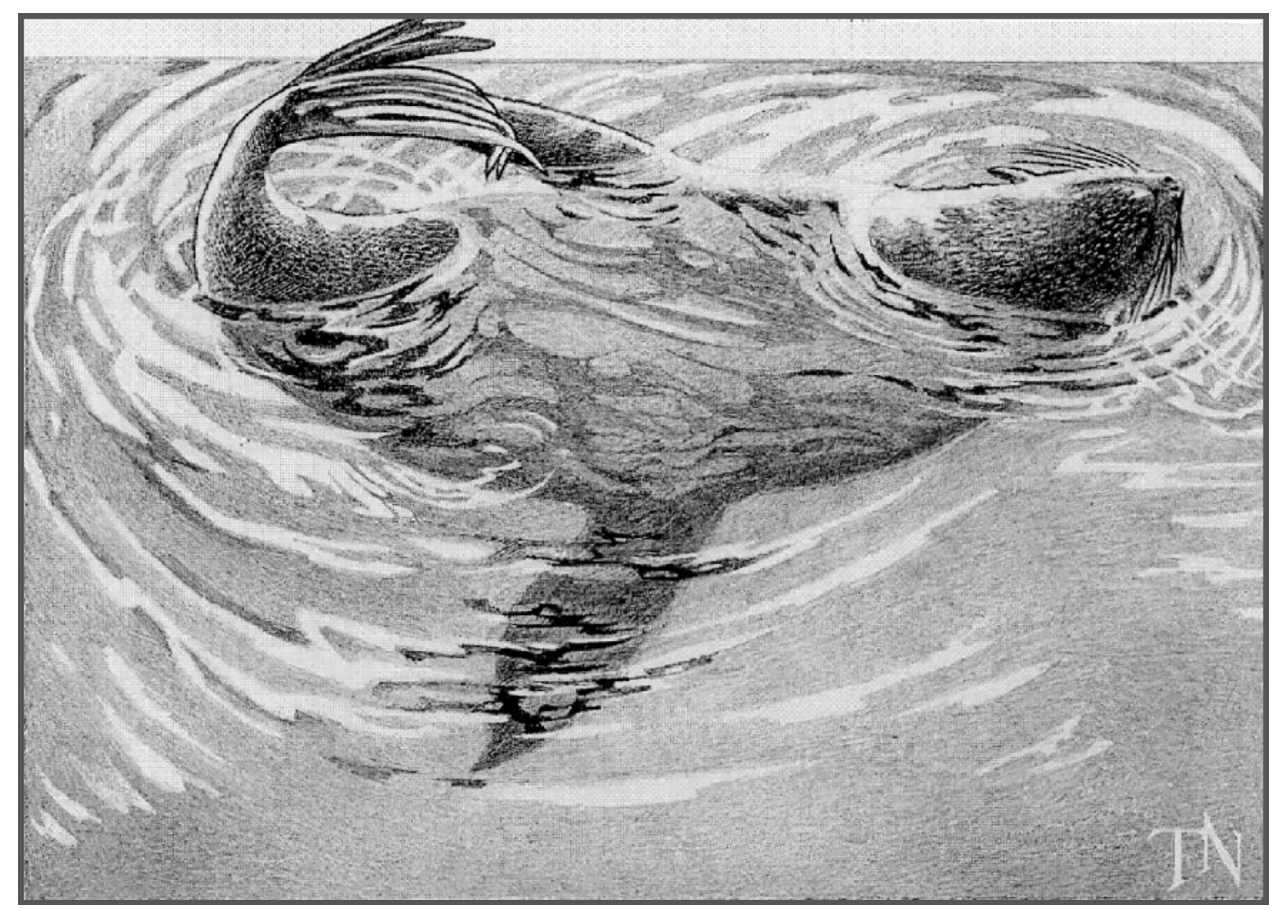

Figure 3 Posture that northern fur seal assumes during USWS in water.

Notes: Seal lying on its left side; the right hemisphere is awake while the left one is sleeping. Reprinted with the permission of Natus Medical, Inc., Middleton, USA. Abbreviation: USWS, unihemispheric slow- wave sleep.

lying at the bottom of the pool and it awoke when it emerged to the surface for breathing. The amount of asymmetrical SWS decreased in water. ${ }^{158}$

\section{Unihemispheric sleep in birds}

Ball et $\mathrm{al}^{60-62}$ reported that gulls slept in bouts alternating between bilateral and unilateral eye closure, which was associated with the presence of Un-Mo sleep. In a screening study, asymmetric eye closure was used for assessing the presence of Un-Mo sleep ${ }^{61,62}$ and unilateral eye closure was found in some species of birds but not in others. Szymczak et $\mathrm{al}^{63}$ recorded episodes of Un-Mo sleep (EEG slow-wave asymmetry) in the European blackbird but failed to observe a concurrent asymmetric eye closure. An absence of EEG asymmetry and of asymmetric eye closure was reported in pigeons. ${ }^{64}$ Thereafter, events of Un-Mo sleep associated with unilateral eye closure were clearly found in pigeons. ${ }^{65}$ Unilateral eye closure during sleep was also observed in Cape white-eye passerine but not in other passerine birds such as malachite sunbird and fan-tailed widowbird. ${ }^{66}$ Rattenborg et al ${ }^{23}$ suggested that Un-Mo sleep should be actually absent in some species of birds, but it may be also that Un-Mo sleep has passed unnoticed because there are difficulties in detecting changes in the EEG wave pattern and eye asymmetry concurrently. ${ }^{64}$ In mallard ducks, the presence of Un-Mo sleep and unilateral eye closure was unmistakably established. ${ }^{67,68}$ It was also indicated ${ }^{23}$ that the "awake" hemisphere seems not to be fully awake but in an intermediate state or in a sort of quiet wakefulness that did not impede the mallard duck being behaviorally awakened as soon as a visual stimulus was presented to the open eye. ${ }^{23}$

An interesting issue concerns the sleep of migrating birds during nonstop long-lasting flights. The general belief is that birds should sleep in flight, ${ }^{69}$ although it has not been technically feasible to record the EEG. Assuming that the motor physiology of migrating birds is not different from that of nonmigrating ones, both BSWS and REM sleep should be unsuitable for flying and sleeping. ${ }^{69}$ Therefore, either they do not sleep at all, dispensing with a large proportion of sleep, or they have only Un-Mo sleep during flight. Rattenborg et $\mathrm{al}^{70}$ studied sleep in the white-crowned sparrow in captivity during migratory and non-migratory seasons. During the migratory season, the birds had only one third of the sleep time they had during nonmigratory seasons. Another migrant, the Swainson's thrush, in captivity had a substantial reduction of night-time sleep during the migration season. The loss of nocturnal sleep is compensated during the day by an increase of drowsiness, total sleep time, daytime micronaps, and episodes of unilateral eye closure/ Un-Mo sleep. ${ }^{71,72}$ 
Un-Mo sleep has been found only in some species of birds. ${ }^{63}$ I may hypothesize for diverse reasons: 1) It was not studied or/and it was not detected. 2) Perhaps some birds do not show Un-Mo sleep because vigilance would be performed in different ways, ie, some birds of the group would supervise and they would be fully awake while others would be allowed to sleep. 3) Some birds do not have or they do not need Un-Mo sleep and antipredation vigilance because they are predators, for example, eagle and owl.

\section{Unihemispheric sleep in domestic chicks}

Domestic chick (Gallus gallus) is an interesting animal model for studying behavior, sleep, and particularly unihemispheric sleep: 1) domestic chicks have a hemispheric lateralization in the control of behavior; ${ }^{73-75}$ 2) hemispheric dominance changes during posthatching development ${ }^{73} 3$ ) chicks can be subjected to performance of specific tasks in which the control of learning is exerted by one or the other hemisphere; ${ }^{76,77}$ 4) it is possible to influence the embryonic development in ovo and, thereby, the hemispheric lateralization. ${ }^{78-80}$

Domestic chicks show a sleep/wakefulness cycle similar to that of mammals. ${ }^{81-83}$ Wakefulness is characterized by an EEG with low amplitude and fast waves; an intermediate phase or drowsiness, with EEG composed of slow and fast waves; BSWS with symmetric EEG with high amplitude and slow waves; and "hypnotic sleep" with symmetric EEG with low amplitude and fast waves (Figure 4A-D); BSWS is interrupted by Un-Mo sleep episodes composed of EEG of highamplitude slow waves in one hemisphere and the contralateral eye shut and fast waves of low amplitude in the other hemisphere and contralateral eye open (Figure 4E).$^{62,83-88}$ During a recording session, domestic chicks showed several Un-Mo sleep events intermingled with BSWS ones. In Figure 4E, a typical event of Un-Mo sleep of nearly 10 seconds' duration is shown. Chicks spent $\sim 1.5 \%-2 \%$ of total time sleeping in Un-Mo sleep.

The Un-Mo sleep pattern of chicks is associated with the posthatching development of brain lateralization. ${ }^{89}$ During the first week (including day 8), behavior is dominated by the left hemisphere, while the right hemisphere dominates during the second week. ${ }^{73,76,90,91}$ During the first week, imprinted chicks showed significantly more left Un-Mo sleep (right eye closure), ${ }^{89}$ which was associated with the fixation of memories of imprinting in the left hemisphere. . $9,92,93^{-1}$ A clear bias toward more right-oriented Un-Mo sleep (left eye closure) was recorded during the second week posthatching, associated with a wake dominance of the right hemisphere. ${ }^{86,89}$
Hemispheric dominance and Un-Mo sleep are also influenced by the egg's incubation. ${ }^{78,88,95}$ Chicks hatched from eggs light-incubated (last 3 days of incubation) showed a significant posthatching bias toward more right Un-Mo sleep (left eye closed), while in chicks coming from eggs dark-incubated, the bias was toward more left USWS (right eye closed) ${ }^{88,95}$ In the egg, the right eye lies adjacent to the shell, and it is stimulated by penetrating light, while the left eye is positioned next to the dense mass of the body and not stimulated by light. ${ }^{94}$ It was suggested ${ }^{88,95}$ that light stimulated the developmental processes of the left hemisphere earlier than those in the right, causing both left hemisphere dominance and more left Un-Mo sleep (right eye closed); instead, the absence of light stimulation favors right hemisphere development processes. In other terms, right hemisphere dominance would be prewired in the embryo in the absence of any external modulator effect. ${ }^{95}$

It is known that the left hemisphere dominates in tasks in which the selection of cues allows stimuli to be classified into categories, while the right hemisphere dominates in spatial analysis and in responses to novelty. ${ }^{75,77,96-98}$ Chicks trained binocularly in a color discrimination task showed subsequently more left Un-Mo sleep (right eye closure), associated with a prevalent engagement of the left hemisphere in learning the task. Another group of chicks subjected to a spatial task showed subsequently more right Un-Mo sleep (left eye closure) related to a prevalent engagement of the right hemisphere in the task. ${ }^{99-101}$

\section{The functions of unihemispheric sleep}

In cetaceans living in an aquatic environment, USWS provides the benefits of both sleep and survival. Concurrently, the open eye and the awake hemisphere allow cetaceans to monitor the environment for predators, particularly when they swim slowly or hover on the water surface. USWS allows them to surface regularly for breathing while sleeping. ${ }^{26,31,49}$ With the open eye and awake hemisphere, cetaceans are able to control the conspecifics to maintain group coherence while swimming in groups. ${ }^{45,46}$ The awake hemisphere ensures efficient motor control over the tail and flippers for swimming or hovering. Living in water, cetaceans face a thermally challenging environment of high heat loss, and USWS allows them to ensure effective thermogenesis continually from muscular tone and activity, mainly from flipper and tail movements for the forward propulsion. In this context, USWS should be an adaptation to the thermal pressure in water. Pillay and Manger ${ }^{102}$ reported that during USWS, the potential heat loss is compensated by the maintenance of 


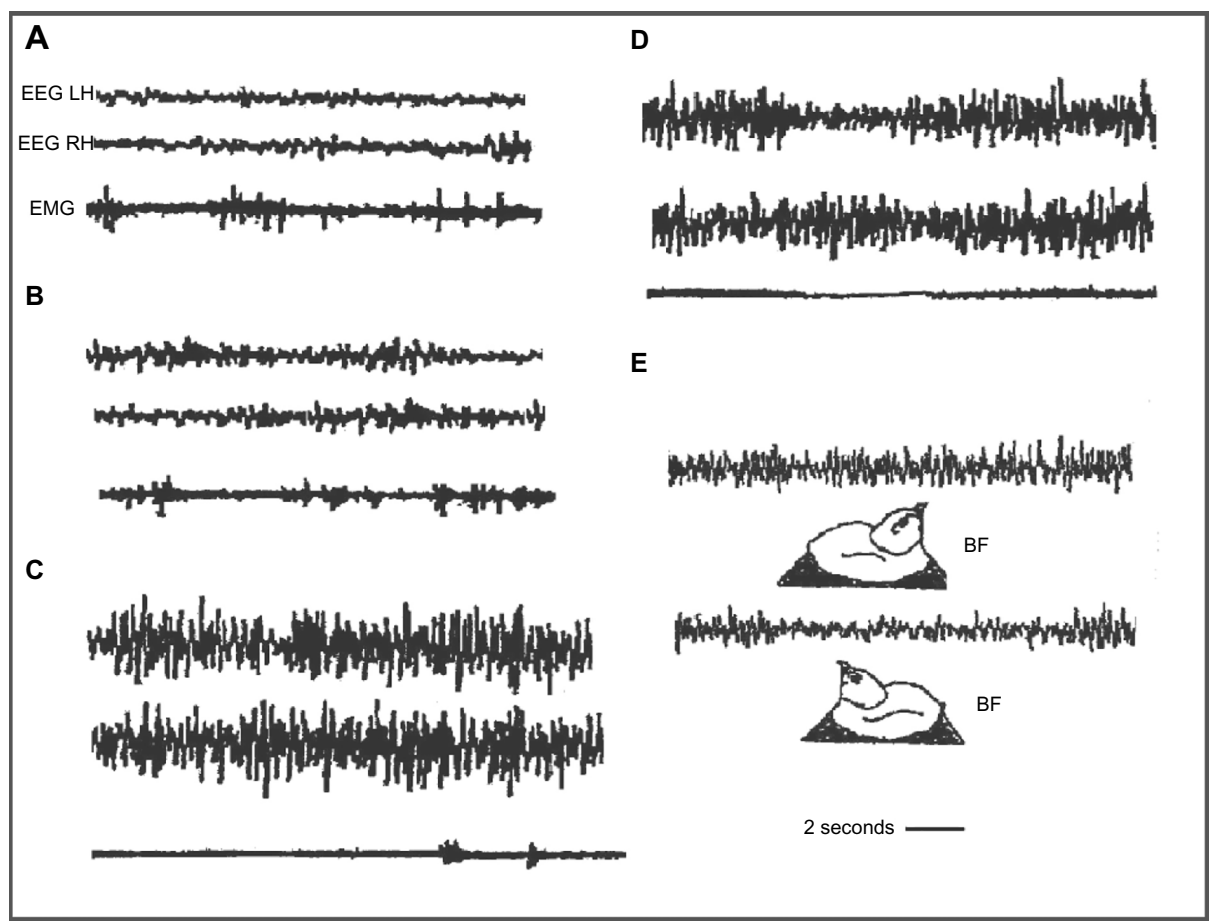

Figure 4 Electrographic recordings in the domestic chick during sleep.

Notes: (A) Wakefulness; (B) intermediate phase; (C) bihemispheric slow-wave sleep; (D) paradoxical sleep; (E) unihemispheric slow-wave sleep. BF indicates bill forward sleep position, with right eye closed and left eye open. Panel (E) has been reprinted from Behavioural Brain Research, Vol I34, Bobbo D, Galvani F, Mascetti GG, Vallortigara G., Light exposure of the chick embryo influences monocular sleep. Pages no 447-466. Copyright (C) 2002 with permission from Elsevier.

Abbreviations: EEG, electroencephalogram; EMG, electromyogram; LH, left hemisphere; $\mathrm{RH}$, right hemisphere.

muscle activity and tone. ${ }^{103}$ In fact, the brain temperature in the awake hemisphere remained constant, while it has been found to be slightly lower in the sleeping one, in agreement with the thermoregulatory role of SWS..$^{11,104,105}$ Two additional features reinforce the role of USWS in maintaining effective thermoregulation. 1) The absence of REM sleep. It is known that REM is accompanied by muscular atonia and inefficient thermoregulation. 2) USWS meets the requirements of the homeostatic regulation of sleep. USWS deprivation causes an increase of the pressure to sleep in the deprived hemisphere and a SWS rebound only in the deprived hemisphere. ${ }^{106}$

The function of USWS in eared seals is slightly different in water and on land. In water, during USWS, seals adopt a special body position at the surface, which allows them to breathe, to paddle with one front flipper, and keep the other three flippers in air probably to reduce the heat loss (thermoregulation). In addition, the open eye and contralateral awake hemisphere allow motor output to the paddling flipper, as well as controlling the surroundings and the approach of predators (sharks, killer whales). In the Steller sea lions, USWS has been recorded while they swim, allowing movement to the surface for breathing and thermoregulation. ${ }^{47}$ On land, the USWS is not linked to breathing, ${ }^{47}$ thermoregulation, and motor control but to a sentinel behavior. The open eye connected to the contralateral awake hemisphere looks away, enabling the control of the environment, coordination with the conspecifics, and detection of predators. Manatees remain motionless at the bottom during all stages of sleep; consequently, USWS may not be connected to the need for breathing, but it is perhaps only used to detect predators. In walruses, ${ }^{158}$ the episodes of USWS and brief opening of one eye would facilitate monitoring of the environment to detect predators and aid in their high level of social activity. ${ }^{158}$ In birds, Un-Mo sleep allows sleep as well as permitting an intermittent necessity for the control of the environment and antipredation. In European blackbirds and domestic chicks, episodes of Un-Mo sleep occur when the bird's bill is pointing forward and parallel to the horizontal plane (BF or bill forward sleep position), ${ }^{63,89}$ which is fully adequate to visually observe the surrounding environment (Figure 4E). In Swainson's thrush, unilateral eye opening during daytime sleep was associated with predator detection and control of environment while recovery processes proceeded..$^{71,72}$ Rattenborg et $\mathrm{l}^{67,68}$ studied the amount of USWS associated with the amount of risk of predation in a group of mallard ducks arranged in a row. They found that ducks at both ends 
of the row showed $150 \%$ higher amount of Un-Mo sleep and associated eye opening than ducks located in central positions. The opened eye of these "sentinel ducks" was directed away from the group, enabling them to detect the approach of a predator. In addition, they quickly awakened (escape behavior) as soon as a threatening visual stimulus was applied to the open eye during an episode of Un-Mo sleep. ${ }^{69}$ Consequently, BSWS time is reduced and the amount of Un-Mo sleep is increased when the risk of predation is high; meanwhile, when that risk is absent or unlikely, BSWS sleep is favored over Un-Mo sleep. ${ }^{23}$ If migrating birds sleep during flight, Un-Mo sleep is the only way that allows efficient muscular activity for recovery and to keep flying. On the contrary, migrating birds drastically reduce sleep during flight, therefore, recovery sleep and Un-Mo sleep episodes were allowed when birds landed to perch and rest on land. . $^{71,72}$

Un-Mo sleep in domestic chicks provides sleep and recovery in the dominant hemisphere and, at the same time, it allows control of the environment (hen or imprinting object) and a probable antipredatory function. An object or a hand moved over the sleeping cage during an episode of Un-Mo sleep caused waking, an immediate startle response, and distress calls. Un-Mo sleep events are short-lasting; in Figure $4 \mathrm{E}$, the event lasts $\sim 10$ seconds, but chicks show several episodes of unihemispheric sleep during a recording session covering $\sim 1.5 \%-2 \%$ of sleep time. The question is: why should the events of Un-Mo sleep be less relevant because they have a short duration or they cover a reduced percentage of sleep time? Several important behavioral patterns occur with reduced duration, but they are of marked biological relevance (eg, antipredatory response, aggression, and copulation). Duration of 10 seconds for each event and for several events should be a sufficient amount of time for an efficacious control of environment and vigilance behavior.

Furthermore, the Un-Mo sleep pattern was unquestionably connected with posthatching standing bias of hemispheric dominance ${ }^{73,89}$ and the dominance in the control of learning behavior. Un-Mo sleep prevailed in the hemisphere that dominated during wakefulness, favoring a recovery process and consolidation of memory. ${ }^{99-101,107-109}$ Because Un-Mo sleep episodes were intermingled with BSWS ones, the dominant hemisphere spent relatively more time sleeping (BSWS plus Un-Mo sleep) than the nondominant one. Concurrently, for the control of the environment, hen and antipredation chicks awoke the nondominant hemisphere and opened the contralateral eye.

\section{Unihemispheric and bihemispheric sleep}

A comparison between USWS and BSWS is important. The first issue stresses that in animals showing only USWS or in those having only episodes of USWS or of Un-Mo sleep, the time spent sleeping is unquestionably lower than that of animals having only BSWS and REM. At first, it seems reasonable to assume that USWS or Un-Mo sleep would be a less efficient way for accomplishing the benefits of sleep for brain and body functions. Cetaceans having only USWS, the amount of which is almost equally shared between both the hemispheres, have approximately half of the sleeping time or, conversely, they are nearly half sleep deprived. Although the awake hemisphere could be considered to be in a state of relaxed waking, ${ }^{24,25}$ the functions of sleep cannot be accomplished during relaxed wakefulness. USWS and the reduction of sleep was probably worked out when in the past, cetaceans returned to water and faced the necessity to breathe, swim/hover, and thermoregulate in a medium favoring heat loss. Consequently, they adopted SWS in one hemisphere at the time and suppressed REM sleep in order to meet the vital needs and, at the same time, to ensure an appropriate brain-and-body recovery process. At any rate, the functions attributed to sleep and behavior seem to be accomplished in dolphins because in captivity, they show good health ${ }^{27,37}$ and they can be trained to learn and memorize very complex tasks.

In seals and birds, USWS episodes are intermingled with BSWS and REM sleep episodes; therefore, a certain reduction of the total time spent sleeping was also evident. The reduction of sleep is higher in the hemisphere that is more often awakened with respect to the other hemisphere that benefits with more sleep. In seals, the reduction of sleep was higher in water than on land because the amount of USWS in water was $66 \%$ of sleep time, while on land, it was $41.6 \% .^{26,49}$ Perhaps, the need for vigilance was more pressing in water; therefore, BSWS and REM sleep were curtailed and USWS was increased.

Birds also showed a reduction of the total time spent sleeping, which was more in one hemisphere than in the other, in favor of vigilance. The amount of vigilance required for risk of predation in animals decreases in parallel with the increase in group size and the position inside the group; edge animals spent approximately twice as much time in vigilance behavior than animals placed centrally. ${ }^{110,111}$ Rattenborg et $\mathrm{al}^{23,68}$ reported that mallard ducks reduced sleep in favor of increasing the likelihood of survival. Probably, in the wild, the role of "sentinel" mallard ducks would be assumed, 
day after day, by different birds; therefore, the reduction of sleep time in one performance can be compensated in the following sleep sessions.

In domestic chicks, the Un-Mo sleep pattern seems to be mainly related to hemispheric dominance. ${ }^{89}$ On the one hand, the reduction of sleep was lower in the dominant hemisphere, allowing for recovery process and memory consolidation. ${ }^{89,99}$ On the other hand, the nondominant hemisphere showed a higher reduction of the time spent sleeping and had a greater role in the control of environment and vigilance.

The relationship between BSWS and Un-Mo sleep was studied in domestic chicks during recovery of sleep after a moderate sleep deprivation ( 8 hours). ${ }^{12}$ During recovery, the total time spent sleeping and time spent in BSWS were both higher in deprived chicks than in nondeprived control ones, in accordance with previous studies in rats. ${ }^{113-115}$ Moreover, the time spent in Un-Mo sleep was equal between deprived and nondeprived chicks, suggesting that even when sleep is impeded by a moderate extension of wakefulness, chicks do not give up to Un-Mo sleep, alertness, and vigilance. Instead, when sleep deprivation is longer and the propensity to sleep is higher, a reduction of Un-Mo sleep in favor of BSWS is preferred and, at the same time, a reduction of alertness and vigilance is also found. ${ }^{116}$

Overall, although USWS curtails a certain amount of sleep, it has not been reported that the behavior and health of cetaceans, birds, and seals would be affected. It may be assumed that these animals benefit by the restoration of brain energy metabolism, efficiency of immune system, thermoregulation, and brain plasticity. Perhaps seals recover sleep when they leave water and rest on land. Migrating birds recover sleep during the daily rest on land, showing USWS episodes for antipredation vigilance, but their body efficiency is not affected. In fact, they can resume an efficient and longlasting flight the next night.

\section{Unihemispheric sleep and neural and neurochemical mechanisms of sleep}

The neural mechanisms of USWS are unknown, and they could only be suggested on the basis of what is known about the sleep/waking cycle in terrestrial mammals and by assuming that both the neural structures and mechanisms involved are almost the same. Cetaceans were terrestrial mammals before becoming aquatic ones; therefore, it is presumed that they preserved the basic sleep/wake neural structures and mechanisms.

Asymmetric eye closure/opening is associated with unihemispheric sleep. An initial issue to clear up is whether unihemispheric sleep is the output of the activity of brain neurochemical circuits or it is only the consequence of the unilateral motor signals that trigger the eye opening and visual input causing the awakening of the contralateral hemisphere. In gulls, it has been insinuated ${ }^{23,62}$ that adverse environmental conditions (ie, the direction of the sun and the wind) could determine the eye to be kept closed and the hemisphere to be asleep. However, the transition from BSWS to USWS in birds may occur in the absence of visual stimuli. ${ }^{117}$ USWS has been recorded in unilaterally and bilaterally blinded chickens. ${ }^{85,118}$ USWS has been recorded in gulls kept in complete darkness. ${ }^{62}$ Furthermore, eye opening during an episode of USWS in dolphins is mainly, but not always, correlated with the awakening of the contralateral hemisphere. Ridgway ${ }^{29}$ reported that the EEG of dolphins remained desynchronized and symmetrical even when one eye was occluded. In birds with lateral eyes (domestic chick and pigeons), the optic fibers cross completely at the optic chiasm, but part of them cross the midline through the subcortical commissures. ${ }^{119}$ Therefore, each hemisphere receives binocular visual projections, which is an anatomicalfunctional feature incompatible with sensory awaking in one hemisphere and sleeping in the other one. Therefore, the assumption that USWS is triggered by a unilateral visual input could be ruled out, although it is unquestionable that the visual input during an USWS episode would have a role in maintaining the contralateral hemisphere in the awakened state, allowing efficient control of the environment. Therefore, USWS may be brought about by endogenous brain mechanisms permitting both adequate brain-restoring processes and adaptative survival behavior.

The neural mechanisms of the waking-sleep cycle are based on the interaction among structures of the brain stem, hypothalamus, and basal forebrain. Sleep-promoting neurons are the gamma-aminobutyric acid-secreting (GABAergic) neurons of the basal forebrain, anterior hypothalamus (ventrolateral preoptic nucleus [VLPO]), midbrain, and pons. Arousal and waking maintenance are promoted by the activity of monoaminergic (MA-ergic) and cholinergic nuclei of posterior hypothalamus, basal forebrain, locus coeruleus, and raphe nuclei. Orexinergic neurons of the middle hypothalamus have the role of sustaining and regulating the activity of waking neural groups. ${ }^{120,121}$ In addition, the low frequency of discharge of noradrenergic and serotonergic neurons during NREM sleep would favor the decrease of muscular tone. Fuller et $\mathrm{al}^{121}$ proposed a flip/flop model for the sleep/waking cycle, in which waking is maintained by the high activity of wake-promoting neural groups that activate the cortex and subcortical structures and, at the same time, 
inhibit sleep-promoting groups. Instead, sleep is triggered when sleep-promoting neurons actively inhibit arousal- and wakefulness-promoting ones.

It may be assumed that the same brain neurochemical groups regulate the sleep/wake cycle of cetaceans, but the mechanisms triggering and maintaining sleep would prevail on one side of the brain, while the mechanisms causing arousal and maintaining waking would prevail on the other side. In other words, there would be a sort of interhemispheric flip/ flop mechanism shifting from one side of the brain to the other. Kedziora et al, ${ }^{122}$ using the model of mammalian arousal ascending system, constructed a mathematical model of USWS. The model included the mutual interaction between wakingpromoting MA-ergic, cholinergic, and orexinergic nuclei and the sleep-promoting VLPOs of the anterior hypothalamus regulated by circadian and homeostatic drives. The central structure of the model is the VLPO nucleus and its interhemispheric and intrahemispheric inhibitory connections (Figure 5).

The main outcome of the model is that USWS would be promoted by interhemispheric or contralateral inhibitory connections between the VLPO nuclei of both sides, while BSWS would be promoted by VLPO intrahemispheric or ipsilateral inhibitory connections to MA-ergic nuclei. The frequency of alternating USWS episodes would be determined by sleep homeostasis and the time constant, ie, the circadian regulation. Both would promote sleep in one hemisphere and waking in the other one.

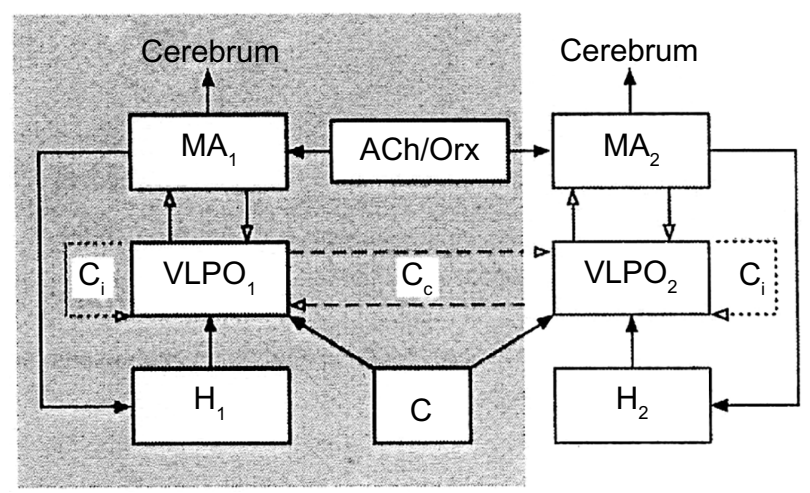

Figure 5 Model of unihemispheric sleep.

Notes: In the shaded and clear areas are shown the structures of the two sides of the brain. Numbers $I$ and 2 indicate the structures and circuits of the two sides of the brain, respectively. Solid arrows indicate excitatory inputs; inhibitory connections are indicated by open arrows. Reprinted from Journal of Theoretical Biology, Vol 3I4, Kedziora DJ, Abeysuriya RG, Phillips AJK, Robinson PA. Physiologically based quantitative modeling of unihemispheric sleep. Pages no 109-119. Copyright ( (20I2) with permission from Elsevier.

Abbreviations: $\mathrm{ACh} / \mathrm{Orx}$, acetylcholine/orexin inputs to MA-ergic; $\mathrm{Cip}$ and $\mathrm{Cco}$, hypothesized ipsilateral and contralateral connections of VLPO, respectively; $\mathrm{H}$ and $\mathrm{C}$, homeostatic and circadian drives, respectively; MA-ergic, monoaminergic nuclei of brain stem and posterior hypothalamus; VLPO, ventrolateral preoptic area.
This model applies for cetaceans' sleep, while for seals and birds, it suggests that the alternation of BSWS, REM sleep, and USWS would depend on the strength of the contralateral inhibitory VLPO connections; when they are weak, BSWS is promoted, whereas when they become temporarily strong, an USWS episode would be produced.

Sleep-promoting neurons of the VLPO of anterior hypothalamus are also thermosensitive. An increase or a decrease of brain temperature causes an increase or a decrease of the firing rate of these neurons, respectively. Mild heating of this area reduces sleep latency, promotes NREM sleep, and SWS, while its cooling causes opposite effects. ${ }^{33,123}$ In cetaceans, another mechanism is brought into play. ${ }^{33}$ If the awake hemisphere's brain temperature becomes slightly warmer ${ }^{33}$ because it is awake, ${ }^{11}$ the firing rate of the VLPO neurons increases and SWS is promoted, whereas if brain temperature in the sleeping hemisphere declines, the firing rate of the thermosensitive neurons also declines, favoring arousal and waking. Data partly support this hypothesis because during USWS of dolphins, the brain temperature was effectively found to be lower in the sleeping hemisphere, but the temperature in the awake hemisphere remained constant. ${ }^{33,104,105}$ The discharge from the locus coeruleus of dolphins was found to be higher in the awake side and lower in the sleeping one. ${ }^{124}$ Continuous discharge of noradrenergic neurons and the secretion of noradrenaline would stimulate glial metabolic rate and heat production. During USWS, the noradrenergic discharge/metabolic rate is asymmetric, being higher in the awake hemisphere and lower in the sleeping one. It has been suggested that these metabolic/brain temperature hemispheric mismatches ${ }^{124}$ play a role in causing the interhemispheric alternation of SWS and wakefulness. In addition, continuous firing by the locus coeruleus as well as raphe nuclei during USWS would allow the maintenance of muscle tone in dolphins for emerging, swimming, and breathing. Finally, the absence of REM sleep seems fully justified because neuronal firing from the locus coeruleus and raphe nuclei ceases completely during REM sleep in terrestrial mammals.

It is more difficult to speculate about the neural mechanism of USWS in seals and birds. Assuming that they possess sleep neural structures similar to those of terrestrial mammals, when an USWS episode is going to be triggered interrupting BSWS, sleep-supporting mechanisms would be briefly inhibited in one hemisphere, causing its awakening/contralateral eye opening, while sleep mechanisms remain dominant in the other hemisphere. The mathematical model ${ }^{122}$ points out that an USWS episode would occur when contralateral 
inhibitory VLPO connections become temporarily strong. When they subsequently become weak, the ipsilateral VLPO inhibitory connections would predominate and BSWS would resume. An important point is the monoamine release during unihemispheric sleep of fur seals. Serotonin, norepinephrine, and histamine release is not lateralized during USWS in fur seals. ${ }^{132,160}$ However, acetylcholine release is lateralized during $\mathrm{USWS}^{131}$ of fur seals, being greater in the hemisphere showing low-voltage EEG pattern (quiet waking). ${ }^{131}$ Perhaps, the asymmetrical release of acetycholine plays a role in the temporary unihemispheric awakening in fur seals.

The sleep/waking mechanisms of the two sides of the brain yield a certain degree of autonomy, higher in cetaceans and lower in seals and birds. However, the coherency of sleep/waking cycles between the two sides would be ruled by an across-the-midline exchange of neural messages. In dolphins, the interhemispheric messages would impede BSWS and allow proper duration of sleep in one hemisphere before being switched to wakefulness. Mukhametov ${ }^{22,32}$ reported that the number of episodes of USWS in dolphins is almost equally distributed between both sides of the brain if they were quantified after a certain number of consecutive sleep sessions. However, in each single session, the number of USWS episodes was higher on one side than on the other. Probably, the propensity to sleep would not be always equal between the hemispheres and if propensity is higher in one of them, the neural circuits promoting sleep would be kept active longer. In dolphins swimming in groups, when sleep propensity nadir is attained in one hemisphere after it is awakened, the other hemisphere goes to sleep and the dolphin changes position in the group, maintaining visual contact and group coherency.

The commissures are the neural structures mediating the midline crossing of neural signals. The corpus callosum should be the first attribution, but it is unusually small in cetaceans $^{33,125}$ and it is almost nonexistent or nonfunctional in birds. ${ }^{126}$ On the one hand, in split-brain cats and humans as well as in humans with callosal agenesis, sleep maintains its bihemispheric pattern. ${ }^{127-129}$ On the other hand, sleep neural mechanisms are located mainly in the brainstem and hypothalamus, so that the subcortical commissures may have the key role of mediating the midline crossing of signals. Michel and Roffwarg, ${ }^{130}$ after a complete longitudinal section of the brain stem of the cat, observed alternating and asynchronous appearances of SWS in the two hemispheres. Mammals having USWS showed a larger posterior commissure compared with those lacking this kind of sleep. ${ }^{23}$ In cetaceans, the posterior commissure is extremely large and the EEG coherence in split-brain cats is disrupted after the additional sectioning of posterior commissure..$^{33,127}$ In cetaceans, the posterior commissure contains more midline-crossed noradrenergic fibers arising from locus coeruleus. ${ }^{23}$ The activity of fibers coming from the locus coeruleus of one side could maintain the cortical activation and waking on the opposite side. In addition, acetylcholine release in fur seals is also lateralized during USWS with a greater release in hemisphere showing desynchronized waking EEG. ${ }^{131}$ However, the main questions are the following: how can locus coeruleus (cholinergic nuclei of one side in fur seals) ${ }^{131}$ promote waking in the contralateral hemisphere and, at the same time, those fibers arising from the other side be ineffective in causing waking in the other hemisphere? Are they inhibited by sleep-promoting neurons such as contralateral VLPO ones? Perhaps the brain structures involved in the sleep/waking cycle interact differently in cetaceans, seals, and birds than in animals having only BSWS and REM sleep.

It has been widely suggested that the shift from wakefulness to sleep could be triggered by the progressive accumulation of putative endogenous somnogens during wakefulness. During sleep, their concentration declines along with the reduction of sleep propensity. Adenosine released by basal forebrain ${ }^{133-135}$ would bilaterally activate GABAergic VLPO sleep-promoting neurons and other nuclei connected to VLPO. ${ }^{136}$ Other chemicals such as melatonin, IL-1, GHRH, and others have also been proposed as putative bilaterally acting somnogens. Probably, these chemicals are also present in the brain of dolphins, seals, and birds; therefore, somnogens' involvement in USWS and Un-Mo sleep cannot be excluded. However, their effect in cetaceans would be unilaterally transient and shifting sides. The action of somnogens on BSWS and USWS pattern of seals and birds would be bilateral but it would be unilaterally blocked, causing a transient ipsilateral hemispheric arousal. After a short period of time, the block would be removed and BSWS resumed.

\section{Hemispheric asymmetries in bihemispheric sleep: local sleep}

In humans, the asymmetries in the EEG pattern during sleep have been associated with different degrees of hemispheric involvement in sleep. Overall, different functions, physiology, and mentation attributed to REM and to NREM sleep would be connected to hemispheric functional lateralization. ${ }^{137}$ This issue is quite controversial because some studies have found certain relationships such as the right hemisphere being mainly involved in REM sleep and the left hemisphere activation during NREM sleep; other studies were unable to detect 
any hemispheric dominance during sleep. Armitage et al ${ }^{138}$ described EEG asymmetry in stage 2 of NREM and SWS, while the EEG pattern was symmetrical in REM sleep. An alpha-rhythm EEG asymmetry during REM sleep in frontal and temporal derivations has been reported, ${ }^{139}$ probably related to emotional reactivity during dreaming. Sekimoto et a ${ }^{140}$ reported a higher number of delta waves in the right hemisphere frontal and central derivations than in the left one, while no asymmetry was found in the other cortical derivations. This asymmetry was attributed to a higher activation of the right hemisphere during wakefulness. The shift of EEG hemispheric asymmetry in the anterior/posterior axis in right-handed humans was explored. ${ }^{141}$ Left hemisphere predominance in the frequency of sleep spindles was found along the anterior posterior axis. In central-parietal derivations, there would be right hemisphere dominance in the delta/theta band during NREM sleep and a left hemisphere dominance in the delta/theta band during REM sleep.

The behavioral awakening occurred more frequently from NREM sleep first in the left hemisphere or first in the right hemisphere, but this hemispheric asymmetry was not found at awakening from REM sleep. ${ }^{142}$ Bertini et al, ${ }^{143}$ using a tactile recognition test at awakening, reported a left-hand/ right hemisphere superiority in the performance at awakening from REM sleep, while no hand/hemisphere difference was observed at awakening from NREM sleep. Subjects tested in a cognitive task after awakening from NREM (stage 2) and from REM sleep showed right hemisphere superiority in the performances after awakening from REM sleep and left hemisphere superiority after awakening from NREM sleep. ${ }^{144}$ Casagrande et al ${ }^{145}$ showed that left hemisphere goes to sleep earlier than the right one. As far as sleep onset is concerned, it was found that right-handed subjects show shorter latencies in the left hemisphere than in the right one, which could be associated with left hemisphere dominance. ${ }^{146}$ In fact, left-handed subjects do not show any significant sleep onset asymmetry.

In rats, at the onset of light period, when the sleep pressure is high, there was a left hemisphere predominance of low-frequency power (parietal derivations) in SWS and there was a shift to right hemisphere predominance when sleep pressure faded out. ${ }^{147}$ After a period of sleep deprivation, the left hemisphere predominance was enhanced during sleep recovery. During REM sleep, there was right hemisphere dominance in the power of the theta band. Recently, the EEG recorded in rats over a period of 48 hours reported significant light/dark changes in hemisphere dominance in delta power during NREM and in the theta power during REM. ${ }^{148}$
Hemispheric asymmetry has been also associated with a use-dependent process. In humans, Cajohem et al ${ }^{149}$ found that a 2-hour light stimulation on the left visual hemifield caused an attenuation of the waking alfa EEG activity and a decrease of EEG delta activity during subsequent sleep in the right visual cortex, but no effect was recorded in the left visual cortex after right visual field stimulation. ${ }^{149}$ However, total sleep and sleep efficiency did not change while comparing experimental and control subjects. The application of aversive stimuli during sleep caused higher changes of frontal alpha activity in left hemisphere than in the right one both in stage 2 of NREM and in REM sleep. ${ }^{150}$ Kettler et a ${ }^{151}$ showed that a right-hand vibration stimulation in right-handed subjects before sleep caused subsequently a higher delta band power in the left hemisphere than in the right one. By contrast, no changes after left-hand stimulation were reported. They proposed that the effect is caused by metabolic activation in the contralateral left somatosensory cortex in response to the task but they also attributed a key role to the standing left hemisphere dominance. However, Cottone et al ${ }^{152}$ reported that vibratory stimulation on a given hand did not disrupt SWS delta band pattern in the contralateral hemisphere, suggesting that human brain can monitor the environment without compromising sleep wave pattern.

In rats, unilateral vibrissae stimulation and the handedness in a task caused an asymmetrical EEG pattern with higher power in the hemisphere contralateral to the side of tactile stimulation and of the preferred paw. ${ }^{153,154}$ This use-dependent pattern is called local or regional sleep, meaning that when one part of the brain is highly stimulated during wakefulness that part would subsequently have more sleep than other parts less or not at all activated. Huber et a ${ }^{155}$ reported a significant increase of SWS intensity in the right parietal region after subjects were subjected to a task of motor rotation adaptation compared to controls submitted to a no-rotation task but under kinematically identical conditions. Subsequently, subjects subjected to an arm immobilization showed a decrease of the somatosensory- and motor-evoked potentials over the contralateral somatosensory cortex and during sleep, SWS was also significantly reduced ${ }^{156}$ over the same cortical area. In domestic chicks, the USWS should be considered a kind of local sleep. ${ }^{100,101}$ In pigeons, the monocular visual stimulation during BS deprivation elicited an increase of SWS and the slope of slow waves only in the hyperpallium connected with the stimulated eye (visually processing region) during recovery but not in the nonvisual mesopallium. ${ }^{157}$ It is suggested that local SWS increase is correlated with local synaptic plastic changes associated 
with the learning task and with improvement in the task performance after sleep. On the other hand, the reduction of SWS would be indicative of local synaptic depression. ${ }^{156}$ When synaptic strength is reduced, local sleep is concurrently reduced. Therefore, cortical plasticity could be associated with local sleep regulation.

\section{Conclusion}

Sleep and wakefulness are opposite brain and body conditions that accomplish different but complementary functions. Sleep is a vulnerable state of almost-complete disconnection from environmental events aimed at a mandatory brain and body recovery, while wakefulness is characterized by intense and necessary interaction with the environment aimed at survival. In some animals, this conflict has been mitigated by adopting a behavioral strategy in which they attempt to survive and recover at the same time. In other terms, they sleep with half of the brain while remaining awake with the other half. For cetaceans, USWS and the removal of BSWS/ REM sleep were the crucial solutions that they adopted when they decided to return to the aquatic environment. It is difficult to know what kind of sleep-waking behavior cetaceans had when they lived on land; did they show BWSW and REM as other terrestrial mammals? Or did they also show USWS events similar to seals? In the first case, adaptation to aquatic conditions would have been a hard endeavor and the influence of natural selection would have been strong. In the second case, the adaptation would have been easier, perhaps just lengthening of and making USWS exclusive. USWS for some species of birds and seals is a transient sleeping behavior, together with BSWS and REM, aimed at controlling the environment and avoiding predation. In domestic chicks and mallard ducks, Un-Mo sleep probably is a legacy from when they lived in the wild. Probably, USWS is present in wild or semiwild birds. In the novel "Le chateau des songes" (The Castle of Dreams), Michel Jouvet (1993) transcribed a diary of a 17-century French physician, naturalist, and lord of a castle called Hugues la Scieve, in which some observations about sleep of birds were reported: "[...] the birds with the neck bent and head hidden under wing, sometimes lying down or on only one leg [...] we were surprised to note that swans and geese slept with only one eye". Finally, I do not resist the temptation of expressing a sort of envy for those animals that have the capacity to disconnect their brain from the environment and send to rest one part of it. Often, this desire arose when I was forced to attend boring social events, conferences, or scientific lectures.

\section{Acknowledgments}

I am grateful to Mr Francesco Battisti for both technical assistance and advice in the editing of the Video Abstract.

\section{Disclosure}

The author reports no conflicts of interest in this work.

\section{References}

1. Pieron H. Le Probléme Physiologique du Somneil. Paris: Masson; 1913.

2. Bennington JH, Heller HC. Restoration of brain energy metabolism as a function of sleep (1995). Prog Neurobiol. 1995;45:347-360.

3. Lewey AJ, Wher TA, Goodwin FK, Newsome D, Marley SP. Light suppresses melatonin secretion in humans. Science. 1980;210: 1267-1269.

4. Sassin JF, Parker DC, Mace JW, Gotlin RW, Johnson LC, Rossman, LG. Human growth hormone release: relation to slow wave sleep and sleepwaking cycle. Science. 1969;165:513-515.

5. Spiegel K, Leproult R, Van Cauter E. Impact of sleep debt on metabolic and endocrine functions. Lancet. 1999;354:1435-1439.

6. Mullington JM. Endocrine function during sleep and sleep deprivation. In: Stickgold R, Walker M, editors. The Neuroscience of Sleep. Philadelphia, PA: Elsevier Inc; 2009:209-212.

7. Mullington JM. Immune function during sleep and sleep deprivation. In: Stickgold R, Walker M, editors. The Neuroscience of Sleep. Philadelphia, PA: Elsevier Inc; 2009:213-217.

8. Obal FJ, Krueger JM. Biochemical regulation of sleep. Front Biosci. $2003 ; 8: 520-550$.

9. Toth LA, Tolley EA, Krueger JM. Sleep as a prognostic indicator during infectious disease in rabbits. Proc Soc Exp Biol Med. 1993; 203:179-192.

10. Renegar KB, Floyd RA, Krueger JM. Effects of short-term sleep deprivation on murine immunity to influenza virus in young adult and senescent mice. Sleep. 1998;21:241-248.

11. McGinty D, Szymusiak R. Keeping cool: a hypothesis about the mechanisms and functions of slow-wave sleep. Trends Neurosci. 1990;13:480-487.

12. Glotzbach SF, Heller HC. Central nervous regulation of body temperature during sleep. Science. 1976;194:537-539.

13. Parmeggiani PL, Rabini C. Sleep and environmental temperature. Arch Ital Biol. 1970;108:369-387.

14. Bach V, Telliez F, Libert J-P. Interaction between sleep and thermoregulation in adults and neonates. Sleep Med Rev. 2002;6: 481-492.

15. Szymusiak R. Thermoregulation during sleep and sleep deprivation. In: Stickgold R, Walker M, editors. The Neuroscience of Sleep. Philadelphia, PA: Elsevier Inc; 2009:218-222.

16. Walker MP. Sleep dependent memory processing. In: Stickgold R, Walker MP, editors. The Neuroscience of Sleep. Philadelphia, PA: Elsevier Inc; 2009:230-240.

17. Walker MP, Stickgold R. Sleep, memory and plasticity. Ann Rev Psychol. 2006;10:139-166

18. Walker MP, Stickgold R. Sleep dependent learning and memory consolidation. Neuron. 2004;44:121-133.

19. Stickgold R, Walker MP. Memory consolidation and reconsolidation: what is the role of sleep? Trends Neurosci. 2005;28:408-415.

20. Tononi G, Cirelli C. Sleep and synaptic homestasis: a hypothesis. Brain Res Bull. 2003;672:143-150.

21. Tononi G, Cirelli C. Sleep function and synaptic homeostasis. Sleep Med Rev. 2006;10:49-62.

22. Mukhametov LM, Supin AY, Polyakova IG. Interhemispheric asymmetry of the electroencephalographic sleep pattern in dolphins. Brain Res. 1977;134:581-584. 
23. Rattenborg NC, Amlaner CJ, Lima SL. Behavioral, neurophysiological and evolutionary perpectives of unihemispheric sleep. Neurosci Biobehav Rev. 2000;24:817-842.

24. Shurley JT, Serafetinides EA, Brooks RE, Elsner R, Kenney DW. Sleep in Cetaceans: I. The pilot whale, Globicephala scammoni. Psychophysiology. 1969;6:230.

25. Serafetinides EA, Shurley JT, Brooks RE. Electroencephalogram of the pilot whale (Globocephala scammoni), in wakefulness and sleep: lateralization aspects. Int J Psychobiol. 1972;2: $129-135$.

26. Mukhametov LM. Unihemispheric slow wave sleep in the brain of dolphins and seals. In: Inoue S, Borbely AA, editors. Endogenous Sleep Subtances and Sleep Regulation. New York, NY: Japan Societies Press; 1985:67-75.

27. Mukhametov LM, Oleksenko AI, Poliakova IG. Quantitative characteristics of the electrocorticographic sleep stages in bottle-nosed dolphin. Neurofisioloziya. 1988;20:532-538. [Article in Russian] [Abstract]

28. Mukhametov LM. Sleep in marine mammals. Exp Brain Res. 1984;8:227-238.

29. Ridgway SH. Asymmetry and symmetry in brain waves from dolphin right left and right hemispheres: some observations after anesthesia, during quiescent hanging behaviour and during visual obstruction. Brain Behav Evol. 2002;60:265-274.

30. Howard RS, Finneran JJ, Ridgway SH. Bispectral index of unihemispheric effects in dolphins. Anesth Analg. 2006;103:626-663.

31. Liamin O, Mukhametov LM. Sleep in cetaceans. Zh Vyssh Nerv Deiat Im I P Pavlova. 2013;63:61-74. [Article in Russian] [Abstract]

32. Mukhametov LM. Unihemispheric slow-wave sleep in the Amazonian dolphin, Inia geoffrensis. Neurosci Lett. 1987;79:128-132.

33. Lyamin OI, Manger PR, Ridgway SA, Mukhametov LM, Siegel JM. Cetacean sleep: an unusual form of mammalian sleep. Neurosci Biobehav Rev. 2008;32:1451-1484.

34. Lilly JC. Comment on cerebral dominance in the dolphin. In: Mountcastle VB, editor. Interhemispheric Relations and Cerebral Dominance. Baltimore: The Johns Hopkins Press; 1962:112-114.

35. Lilly JC. Animals in aquatic environments: adaptation of mammals to the ocean. In: Dill DB, Adolph EF, Wiber CG, editors. Handbook of Physiology: Adaptation to Environment. Washington, DC: American Physiological Society; 1964:741-747.

36. Supin AY, Mukhametov LM, Ladygina TF, Popov VV, Mass AM, Poliakova IG. Electrophysiological Studies of the Brain of Dolphins. Moscow: Nauka; 1978. [Cited by Mukhametov et al., 1984].

37. Mukhametov LM, Oleksenko AI, Polyakova IG. The Black Sea bottlenose dolphin: the structure of sleep. In: Sokolov VE, Romanenko VE, editors. The Black Sea Bottlenose Dolphin. Moscow: Nauka; 1997: 492-512. [Cited by Lyamin et al., 2008].

38. Lyamin OI, Mukhametov LM, Siegel JM. Relationship between sleep and eye state in Cetaceans and Pinnipeds. Arch Ital Biol. 2004;142:557-568.

39. Oleksenko AI, Lyamin OI. Rest and active states in Amazonian dolphins (Inia geoffrensis). J Sleep Res. 1994;3(suppl 1):318.

40. Lyamin OL, Mukhametov LM, Siegel JM, Nazarenko EA, Polyakova IG, Shpak OV. Unihemispheric slow wave sleep and state of the eyes in a white whale. Behav Brain Res. 2002;129:125-129.

41. Flanagan WF. Nocturnal behaviour of captive small cetaceans. I: the bottlenose dolphin (Tursiops truncatus). Sleep Res. 1997;3:84.

42. Flanagan WF. Nocturnal behaviour of captive small cetaceans. II: the beluga whale, Delphinapterus leucas. Sleep Res. 1997;3:85.

43. Shpak OV, Lyamin OL, Manger PR, Siegel JM, Mukhametov LM. Rest and activity states in Commerson's dolphin (Cephalorhynchus commersonii). Zh Evol Biokhim Fiziol. 2009;45:97-104. [Article in Russian].

44. Supin YA, Mukhametov LM. Some mechanisms of the unihemispheric slow wave sleep in dolphins. In: Sokolov VE, editor. Electrophysiology of Sensory Systems in Marine Mammals. Moscow: Nauka; 1986:188-207. [Cited by Rattenborg et al., 2000].
45. Goley PD. Behavioral aspects of sleep in Pacific white-sided dolphins (Lagenorhynchus obliquidens, Gill 1865). Mar Mam Sci. 1999;15:104-1064.

46. Gnone G, Benoldi C, Bonsignori B, Fognami P. Observations on rest behaviours in captive bottlenose dolphin (Tursiops truncatus). Aquat Mam. 2001;27:29-33.

47. Lyamin OI, Chetyrbok IS. Unilateral EEG activation during sleep in the Cape fur seal, Arctocephalus pusillus. Neurosci Lett. 1992;143:263-266.

48. Lyamin OI, Lapierre JL, Kosenko PO, Mukhametov LM, Siegel JM. Electroencephalogram asymmetry and spectral power during sleep in northern fur seal. J Sleep Res. 2008;17:154-165.

49. Mukhametov LM, Lyamin OI, Poliakova IG. Interhemispheric asynchrony of the sleep EEG in northern fur seals. Experientia. 1985;41:1034-1035.

50. Lyamin OI, Pavlova IF, Kosenko PO, Mukhametov LM, Siegel JM. Regional differences in cortical electroencephalogram (EEG) slow wave activity and interhemispheric EEG asymmetry in the fur seal. J Sleep Res. 2012;21:603-611.

51. Lyamin OI, Oleksenko AI, Mukhametov LM. Paradoxical sleep in northern fur seals in water and on land. J Sleep Res. 1996;3 -(suppl 1):259

52. Mukhametov LM, Supin AY, Lyamin OI. Interhemispheric asymmetry of the EEG during sleep in marine mammals. In: Onani T, editor. Neurobiology of Sleep-Wakefulness Cycle. Tbilisi: Matsniereba; 1988:147-159. [Cited by Rattenborg et al., 2002].

53. Lyamin OI. The ontogeny development of the interhemispheric asymmetry of the EEG during slow wave sleep in northern fur seals J High Nerve Act. 1987;37:157-159. [Abstract].

54. Lyamin OI, Cetyrbock IS. Interhemispheric asymmetry of the electrocorticogram during slow wave sleep in pups of Stellar's sea lions. Physiology of Marine Animals. All-Union Conference, Apatiti; 1989:99. [Cited by Lyamin OI, Cetyrbock IS, 1992].

55. Lyamin OI, Oleksenko AI, Polyakova IG. Sleep and wakefulness in pups of arp seal Phagophilus groenlandica. J High Nerve Act. 1989;39:1061-1069. [Article in Russian] [Abstract].

56. Lyamin OI. Sleep in the harp seal (Pagophilus groenlandica). Comparison of sleep on land and in water. J Sleep Res. 1993;2:170-174.

57. Castellini MA, Milsom WK, Berger RJ, et al. Patterns of respiration and heart rate during wakefulness and sleep in elephant seal pups. Am J Physiol. 1994;266:R863-R869.

58. Milsom WK, Castellini MA, Harris M, et al. Effects of hypoxia and hypercadmia on patterns of sleep-associated apnea in elephant seal pups. Am J Physiol. 1996;271:R1017-R1024.

59. Mukhametov LM, Lyamin OI, Chetyrbok IS, Vassilyev AA, Diaz RP. Sleep in an Amazonian manatee, Trichechus inunguis. Experientia. 1992;48:417-419.

60. Ball NJ, Shaffery JP, Opp MR, Carter RL, Amlaner CJ. Asynchronous eye-closure of birds. Sleep Res. 1985;14:87.

61. Ball NJ, Weave GE, Amlaner CJ. The incidence of hemispheric sleep in birds. Sleep Res. 1986;15:58.

62. Ball NJ, Amlaner CJ, Shaffery JP, Opp MR. Asynchronous eye closure and unihemispheric quiet sleep of birds. In: Koella WP, Obal F, Schulz H, Visser P, editors. Sleep 86. New York, NY: Gustav Fischer; 1988:151-153.

63. Szymczak JT, Kaiser W, Helb HW, Beszczynska B. A study of sleep in the European blackbird. Physiol Behav. 1996;60:1115-1120.

64. Tobler I, Borbely AA. Sleep and EEG spectra in the pigeon (Columba livia) under baseline conditions and after sleep deprivation. J Comp Physiol A. 1988;163:729-738.

65. Rattenborg NC. Unilateral eye closure and interhemispheric EEG asymmetry during sleep in the pigeon (Columba livia). Brain Behav Evol. 2001;58:323-332.

66. Wellmann AE, Downs CT. A behavioural study of sleep patterns in the malachite sunbird, Cape white-eye and fan-tailed widowbird. Anim Behav. 2009;77:61-66. 
67. Rattenborg NC, Amlaner CJ, Lima SL. Period amplitude analysis of avian unihemispheric quiet sleep. Sleep. 1999;22:S73.

68. Rattenborg NC, Lima SL, Amlaner CJ. Facultative control of avian unihemispheric sleep under the risk of predation. Behav Brain Res. 1999;105:163-172.

69. Rattenborg NC. Do birds sleep in flight? Naturvissenschaften. 2006;93:413-425

70. Rattenborg NC, Mandt BH, Obermeyer WH, et al. Migratory sleeplessness in the white-crowned sparrow (Zenotrichia leucophrys gambelii). PLoS Biol. 2004;2:924-936.

71. Fuchs T, Haney A, Jechura J, Moore FR, Bingman VP. Daytime naps in night-migrating birds: behavioural adaptation to seasonal sleep deprivation in the Swainson's thrush (Catharus ustulatus). Anim Behav. 2006;72:951-958

72. Fuchs T, Maury D, Moore FR, Bingman VP. Daytime micro-naps in a nocturnal migrant: an EEG analysis. Biol Lett. 2009;5:77-80.

73. Andrew RJ. Behavioural development and lateralization. In: Rogers LJ, Andrew RJ, editors. Comparative Vertebrate Lateralization. Cambridge: Cambridge University Press; 2002:157-205.

74. Rogers LJ, Andrew RJ. Comparative Vertebrate Lateralization. Cambridge: Cambridge University Press; 2002.

75. Vallortigara G, Rogers LJ. Survival with an asymmetrical brain: advantages and disadvantages of cerebral lateralization. Behav Brain Sci. $2005 ; 28: 575-589$

76. Vallortigara G, Zanforlin M, Cailotto M. Right-left asymmetry in position learning of male chicks. Behav Brain Res. 1988;27:189-191.

77. Vallortigara G, Regolin L, Bortolomiol G, Tommasi L. Lateral symmetries in eye use due to preference during visual discrimination learning in eye in chicks. Behav Brain Res. 1996;74:135-143.

78. Rogers LJ. Light experience and asymmetry of brain function. Nature. 1982;297:223-225.

79. Rogers LJ. Development of lateralization. In: Andrew RJ, editor. Neural and Behavioural Plasticity: The Use of Domestic Chick as a Model. Oxford: Oxford University Press; 1991:507-535.

80. Chiandretti C, Vallortigara G. Effects of embryonic light stimulation on the ability to discriminate left from right in the domestic chick. Behav Brain Res. 2009;198:240-246.

81. Klein M, Michel F, Jouvet M. Etude polygraphique du somneil chez les oiseaux. CR Soc Biol. 1964;158:90-103.

82. Goodman IJ. The study of sleep in birds. In: Goodman IG, Schein MW, editors. Birds, Brain and Behaviour. New York, NY: Academic Press; 1974:133-152.

83. Ookawa T, Takagi K. Electroencephalograms of free behavioural chicks at various developmental ages. Jap J Physiol. 1968;18:87-99.

84. Spooner C. Observations on the Use of Chick in the Pharmacological Investigation of Central Nervous System [Ph.D. dissertation]. UCLA: Los Angeles, CA; 1964.

85. Ookawa T. Electroencephalograms recorded from telencephalon of blinded chickens during behavioural sleep and wakefulness. Poult Sci. 1971;50:731-736.

86. Rogers LJ, Chaffey G. Lateralized patterns of sleep activity in the developing chick brain. Proc Aust Neurosci Soc. 1994;5:95.

87. van Luijtelaar EL, van der Grinten CPM, Blokhuis HJ, Coenen AML. Sleep in the domestic hen (Gallus domesticus). Phisiol Behav. 1987;41:409-414.

88. Bobbo D, Galvani F, Mascetti GG, Vallortigara G. Light exposure of chick embryo influences monocular sleep. Behav Brain Res. 2002;134:447-466.

89. Mascetti GG, Rugger M, Vallortigara G. Visual lateralization and monocular sleep in the domestic chick. Cogn Brain Res. 1999;7:451-463.

90. Andrew RJ. The development of visual lateralization in the domestic chick. Behav Brain Res. 1988;29:201-209.

91. Rashid N, Andrew RJ. Right hemisphere advantages for topographical orientation in the domestic chick. Neuropsychologia. 1989;27:937-948.

92. Horn G. Neural basis of recognition memory investigated through an analysis of imprinting. Philos Trans R Soc London B. 1990;329:133-142.
93. McCabe BJ. Hemispheric asymmetry of learning-induced changes. In: Andrew RJ, editor. Neural and Behavioural Plasticity: The Use of the Domestic Chick as a Model. Oxford: Oxford University Press; 1991:262-276.

94. Kovach JKJ. Spatial orientation of the chick embryo during the last five days of incubation. Comp Physiol Psychol. 1968;66:283-288.

95. Mascetti GG, Vallortigara G. Why do birds sleep with one eye open? Light exposure of chick embryo as a determinant of monocular sleep. Curr Biol. 2001;11:971-974.

96. Gaston KE, Gaston MG. Unilateral memory after binocular discrimination training: left hemisphere dominance in the chick? Brain Res. 1984;303:190-193.

97. Vallortigara G. Comparative neuropsychology of the dual brain: a stroll through left and right animal' perceptual worlds. Brain Lang. 2000;73:189-219.

98. Vallortigara G, Andrew RJ. Lateralization of responses to change of in the model partner by chicks. Anim Behav. 1991;41:187-194.

99. Mascetti GG, Rugger M, Vallortigara G, Bobbo D. Monocularunihemispheric sleep and visual discrimination learning in the domestic chick. Exp Brain Res. 2007;176:70-84.

100. Nelini C, Bobbo D, Mascetti GG. Local sleep: spatial learning task enhances sleep in right hemisphere of domestic chick (Gallus gallus). Exp Brain Res. 2010;205:195-204.

101. Nelini C, Bobbo D, Mascetti GG. Monocular learning of a spatial task enhances sleep in the right hemisphere of domestic chicks (Gallus gallus). Exp Brain Res. 2012;218:381-388.

102. Pillay $P$, Manger PR. Testing thermogenesis as a basis for the evolution of cetaceans sleep phenomenology. J Sleep Res. 2004;13:353-358.

103. Manger PR, Ridgway SH, Siegel JM. The locus coeruleus complex of the bottlenose dolphin (Tursiops truncatus) as revealed by tyrosine hydroxilase immunohistochemistry. J Sleep Res. 2003;12: 149-155.

104. Kovalzon VM. Brain temperature variations and ECoG in freeswimming bottlenose dolphin. In: Koella WP, Levin P, editors. Sleep 1976: Third European Congress of Sleep Research. Montpellier, Basel: Karger; 1977:239-241.

105. Kovalzon VM, Mukhametov LM. Temperature variations in the brain corresponding to unihemispheric slow wave sleep in dolphins. $J$ Evol Biochem Physiol. 1982;18:307-309.

106. Oleksenko AI, Mukhametov LM, Polyakova IG, Supin AY, Kovalzon VM. Unihemispheric sleep deprivation in bottlenose dolphins. J Sleep Res. 1992;1:40-44.

107. Horne JA. Why We Sleep? The Functions of Sleep in Humans and Animals. New York, NY: Oxford University Press; 1988.

108. Horne JA, Minard A. Sleep and sleepiness following a behaviourally active day. Ergonomics. 1985;28:567-575.

109. Horne JA, Welmsley B. Daytime visual load and the effects upon human sleep. Psychophysiology. 1976;13:115-120.

110. Bednekoff PA, Ritter R. Vigilance in Nxai Pan springbok, Antidorcas marsupialis. Behaviour. 1994;129:1-11.

111. Elgar MA. Predator vigilance and group size in mammals and birds: a critical review of the empirical evidence. Biol Rev. 1989;64:13-33.

112. Bobbo D, Nelini C, Mascetti GG. Binocular and monocular/ unihemispheric sleep in the domestic chick (Gallus gallus) after a moderate sleep deprivation. Exp Brain Res. 2008;185:421-427.

113. Borbely A, Neuhaus HU. Sleep deprivation: effects on sleep and EEG in the rat. J Comp Physiol. 1979;133:71-87.

114. Borbely AA, Tobler I, Hanagasioglu M. Effects of sleep deprivation on sleep and EEG spectra in the rat. Behav Brain Res. 1984;14: $171-182$.

115. Tobler I, Scherschlicht R. Sleep and EEG slow-wave activity in the domestic cat. Behav Brain Res. 1990;37:109-118.

116. Boerema AS, Riedstra B, Strijkstra AM. Decrease in monocular sleep after sleep deprivation in domestic chicken. Behaviour. 2003;140:1415-1420.

117. Rogers LJ. The Development of Brain and Behaviour in the Chicken. Wallingford: CAB International; 1995. 
118. Tarao M, Ookawa T. On the encephalogram in the unilateral optic enucleated chick. Poult Sci. 1969;48:1516-1517.

119. Rogers LJ. Behavioural, structural and neurochemical asymmetries in the avian brain: a model system for studying visual development and processing. Neuroci Biobehav Rev. 1996;20:487-503.

120. Saper CB, Chou TC, Scammell TE. The sleep switch: hypothalamic control of sleep and wakefulness. Trend Neurosci. 2001;24:726-731.

121. Fuller PM, Gooley JJ, Saper CB. Neurobiology of sleep-wake cycle: sleep architecture, circadian regulation and regulatory feedback. Sleep. 2006;21:482-493.

122. Kedziora DJ, Abeysuriya RG, Phillips AJK, Robinson PA. Physiologically based quantitative modelling of unihemispheric sleep. $J$ Theor Biol. 2012;314:109-119.

123. Szymusiak R, Steininger T, Alam N, McGinty D. Preoptic area sleepregulating mechanisms. Arch Ital Biol. 2001;139:77-92.

124. Ridgway SH, Houser D, Finneran JJ, et al. Functional imaging of dolphin brain metabolism and blood flow. J Exp Biol. 2006;209: 2902-2910.

125. Tapley RG, Ridgway SH. Corpus callosum size in delphinid Cetaceans. Brain Behav Evol. 1994;44:156-165.

126. Cuenod M. Commissural pathways in interhemispheric transfer of visual information in the pigeon. In: Schmitt FO, Worden FG, editors. The Neuroscience Study Program. Cambridge, MA: MIT Press; 1974:21-29.

127. Berlucchi G. Electroencephalographic studies in spli-barin cats. Electroencephalogr Clin Neurophisiol. 1996;20:348-356.

128. Montplaisir J, Nielesen T, Cote J, Boivin D, Rouleau I, Lapierre G. Interhemispheric EEG coherence before and after partial callosotomy Clin Electroencephalogr. 1990;21:42-47.

129. Nielsen T, Mountplasir J, Lassonde M. Decreased Interhemispheric coherence during sleep in agenesis of corpus callosum. Eur Neurol. 1993;33:173-176.

130. Michel F, Roffwarg HP. Chronic split brainstem preparation: effect on sleep-waking cycle. Experientia. 1967;23:126-128.

131. Lapierre JL, Kosenko PO, Lyamin OI, Kodama T, Mukhametov LM, Siegel JM. Cortical acetylcholine release is lateralized during asymmetrical slow-wave sleep in northern fur seals. $J$ Neurosci. 2007;27:11999-12006.

132. Lapierre J, Kosenko PO, Kodama T, et al. Symmetrical serotonin release during asymmetrical slow-wave sleep: implications for the neurochemistry of wake-sleep states. J Neurosci. 2013;33:2555-2561.

133. Porkka-Heiskanen T, Strecker RE, Thakkar M, Bjorkum AA, Greene RW, McCarley RW. Adenosine: a mediator of sleep inducing effects of prolonged wakefulness. Science. 1997;276:1265-1268.

134. Porkka-Heiskanen T, Alanko L, Kalinchuck A, Stenberg D. Adenosine and sleep. Sleep Med Rev. 2002;6:321-332.

135. Schwierin B, Borbély AA, Tobler I. Effects of N6-cyclopentyladenosine and caffeine on sleep regulation in the rat. Eur J Pharmacol. 1996;300:163-171.

136. Marairty S, Rainnie D, McCarley R, Greene R. Disinhibition of ventrolateral preoptic area sleep-active neurons by adenosine: a new mechanism for sleep promotion. Neuroscience. 2004;123:451-457.

137. Golstein L, Stoltzfus NW, Gardock JF. Changes in interhemispheric amplitude relationships in the EEG during sleep. Physiol Behav. 1972;8:811-815.

138. Armitage R, Hoffmann R, Loewy D, Moffitt A. Variations in periodanalysed EEG asymmetry in REM and NREM. Psychophysiology. 1989;26:329-336.

139. Benca RM, Obermeyer WH, Larson CL, et al. EEG alpha power and alfa power asymmetry in sleep and wakefulness. Psychophysiology. 1999;36:430-436.
140. Sekimoto M, Kato M, Kajimura N, Watanabe T, Takahashi K, Okuma T. Asymmetric interhemispheric delta waves during all-night sleep in humans. Clin Neurophysiol. 2000;111:924-928.

141. Roth C, Achermann P, Borbely AA. Frequency and state specific hemispheric asymmetries in the human sleep EEG. Neurosci Lett. 1999;271:139-142.

142. Ikeda K, Morotomi T. Asymmetries of behavioural awakenings during nocturnal sleep in humans. Jpn J Physiol Psichol Psichophysiol. 1994;12:39-44.

143. Bertini M, Violani C, Zoccolotti P, Antonelli A, Di Stefano L. Right cerebral activation in REM sleep: evidence from a unilateral tactile recognition test. Psichophysiology. 1984;21:418-423.

144. Gordon HV, Frooman B, Lavie P. Shift in cognitive asymmetries between wakings from REM and NREM sleep. Neuropsichologia. 1982;20:99-103.

145. Casagrande M, Violani C, De Gennaro L, Braibanti P, Bertini M. Which hemisphere falls asleep first? Neuropsichologia. 1995;33:815-822.

146. Casagrande M, Bertini M. Laterality of sleep onset process: which hemisphere goes to sleep first? Biol Psychol. 2008;77:76-80.

147. Wyazovskiy V, Borbely AA, Tobler I. Interhemispheric sleep EEG asymmetry in the rat is enhanced by sleep deprivation. J Neurophysiol. 2002;88:2280-2286.

148. Gene L, Esteban S, Gonzalez J, et al. Asymmetric sleep in rats. Laterality. 2012;17:1-17.

149. Cajohem C, Di Biase R, Imai M. Interhemispheric EEG asymmetries during unilateral bright light exposure and subsequent sleep in humans. Am J Physiol Regul Integr Comp Physiol. 2008;294:R1053-R1060.

150. Flo E, Steine I, Blagstad T, Gronli J, Pallesen S, Portas CM. Transient changes in frontal alpha asymmetry as a measure of emotional and physical distress during sleep. Brain Res. 2011;1367:234-249.

151. Kettler H, Dijk DJ, Borbely A. Effect of unilateral somatosensory stimulation prior to sleep on the sleep EEG in humans. J Sleep Res. 1994;3:159-164.

152. Cottone LA, Adamo D, Squires NK. The effect of unilateral somatosensory stimulation on hemispheric asymmetries during slow wave sleep. Sleep. 2004;27:63-68.

153. Wyazovskiy V, Borbely AA, Tobler I. Unilateral vibrissae stimulation during waking induces interhemispheric EEG asymmetry during subsequent sleep in the rat. J Sleep Res. 2000;9:367-371.

154. Wyazovskiy V, Tobler I. Handedness leads to interhemispheric EEG asymmetry during sleep in the rat. $J$ Neurophysiol. 2008;99:969-975.

155. Huber R, Ghilardi MF, Massimini M, Tononi, G. Local sleep and learning. Nature. 2004;430:78-81.

156. Huber R, Ghilardi MF, Massimini M, et al. Arm immobilization causes cortical plastic changes and locally decrease sleep slow wave activity. Nat Neurosci. 2006;9:1169-1176.

157. Lesku J, Vyssotski A, Martinez-Gonzalez D, Wilzeck C, Rattenborg NC. Local sleep homeostasis in the avian brain: convergence of sleep function in mammals and birds? Proc Biol Sci. 2011;278:2419-2428.

158. Lyamin OI, Kosenko PO, Vyssotski AL, Lapierre JL, Siegel JM, Mukhametov LM. Study of sleep in a Walrus. Dokl Biol Sci. 2012; 444:188-191.

159. Mukhametov LM. The absence of paradoxical sleep in dolphins. In: Koella WP, Obal F, Schulz H, Visser P, editors. Sleep'86. Stuttgart, New York, NY: Gustav Springer Verlag; 1988:154-156.

160. Lyamin OI, Lapierre JL, Kosenko PO, et al. Monoamine release during unihemispheric sleep and unihemispheric waking in the fur seal. Sleep. Epub 2015 Dec 22. 


\section{Publish your work in this journal}

Nature and Science of Sleep is an international, peer-reviewed, open access journal covering all aspects of sleep science and sleep medicine, including the neurophysiology and functions of sleep, the genetics of sleep, sleep and society, biological rhythms, dreaming, sleep disorders and therapy, and strategies to optimize healthy sleep. The journal welcomes

original research, clinical \& epidemiological studies, reviews \& evaluations, case reports and extended reports. The manuscript management system is completely online and includes a very quick and fair peerreview system, which is all easy to use. Visit http://www.dovepress.com/ testimonials.php to read real quotes from published authors.

Submit your manuscript here: http://www.dovepress.com/nature-and-science-of-sleep-journal 